\title{
Impact of lower extremity muscle strength on the clinical outcome of patients with allogeneic hematopoietic stem cell transplantation
}

Shin Kondo ( $\sim$ skondo@tokushima-u.ac.jp )

Tokushima Daigaku Byoin https://orcid.org/0000-0001-6985-1565

Kumiko Kagawa

Tokushima Daigaku Byoin

Takashi Saito

Kobe Daigaku Daigakuin Hokengaku Kenkyuka Igakubu Hoken Gakka

Masahiro Oura

Tokushima Daigaku Byoin

Kimiko Sogabe

Tokushima Daigaku Byoin

Takeshi Harada

Tokushima Daigaku Byoin

Shiro Fujii

Tokushima Daigaku Byoin

Shingen Nakamura

Tokushima Daigaku Byoin

Hirokazu Miki

Tokushima Daigaku Byoin

Nori Sato

Tokushima Daigaku Byoin

Rei Ono

Tokushima Daigaku Byoin

Masahiro Abe

Tokushima Daigaku Byoin

Shinsuke Katoh

Tokushima Daigaku Byoin

\section{Research Article}

Keywords: hematopoietic stem cell transplantation, muscle strength, non-relapse mortality, Overall survival, sarcopenia 
Posted Date: April 28th, 2021

DOl: https://doi.org/10.21203/rs.3.rs-306279/v1

License: (c) (i) This work is licensed under a Creative Commons Attribution 4.0 International License. Read Full License 


\section{Abstract}

Purpose Muscle strength decline is reported to predict mortality in many cancers. However, there is little knowledge of the relation between muscle strength decline and clinical outcome of allogeneic hematopoietic stem cell transplantation (allo-HSCT). This study aimed to determine the impact of pretransplant lower extremity muscle strength (LEMS) on post-transplant overall survival (OS) and nonrelapse mortality (NRM).

Methods In this retrospective cohort study, 86 adult patients underwent allo-HSCT during 2012-2020. LEMS was defined as knee extension force divided by patient's body weight. The patients were divided into low, middle, and high LEMS groups based on pre-transplant LEMS. OS was measured using the Kaplan-Meier method and the Cox proportional hazards model. Cumulative incidence of NRM was evaluated using the Fine and Gray method, with relapse considered as a competing risk event.

Results Probability of OS was significantly lower in the low and middle LEMS groups (hazard ratio [HR] 2.98, $p=0.020$ and HR 2.68, $p=0.034$, respectively) than in the high LEMS group on multivariate analysis. OS at 5 years was $26.0 \%, 36.5 \%$, and $72.5 \%$ in the low, middle, and high LEMS group, respectively. Risk of NRM was significantly lower in the low LEMS group (HR 5.62, $p=0.038$ ) than in the high LEMS group.

Conclusions Pre-transplant LEMS was a significant factor in predicting OS and NRM.

\section{Introduction}

Allogeneic hematopoietic stem cell transplantation (allo-HSCT) is a potential curative treatment for patients with high-risk hematological malignancies. However, patients who have undergone allo-HSCT may have severe treatment-related side effects and complications including infections and graft versus host disease (GVHD). Transplant-related mortality rate is an additional major problem. In Japan, an "Annual Report of Nationwide Survey 2019" [1] reports a 1-year survival rate of $64.2 \%$ in patients with any disease who received allogeneic transplants, with a premature mortality rate of one in three.

Pre-transplant physical function has been reported to be related to post-transplant survival [2, 3], and muscle strength is a factor that directly affects these physical functions. Although muscle strength has been reported to be associated with survival in healthy adults [4] and in patients with cancer [5], there are no reports on its association with long-term prognosis in allo-HSCT. As a factor related to muscle strength, skeletal muscle mass measured by computed tomography (CT) imaging has been reported to be associated with long-term prognosis after transplantation [6-8]. However, problems with this measurement method are that there is risk of radiation exposure and only a few facilities can perform the measurement because only they have the required software for measurement analysis. In contrast, muscle strength measurements are low risk, can be performed at any time, and are useful for screening physical function before transplantation. 
In recent years, maintenance or improvement in lower extremity muscle strength (LEMS) has been reported to be possible by exercise intervention during induction therapy before transplantation [9]. If the relationship between pre-transplant LEMS and long-term prognosis can be clarified, then it can be a target of pre-transplant exercise intervention. Therefore, in this study, we investigated the impact of pretransplant LEMS on OS, non-relapse mortality (NRM), and early adverse events after allo-HSCT.

\section{Materials And Methods}

\section{Patients}

This was a retrospective cohort study involving 96 consecutive patients (aged $\geq 18$ years) who had undergone allo-HSCT between January 1, 2012 and November 30, 2020. LEMS data were missing in 10 patients, so 86 patients with complete LEMS data were included in the analysis. After discharge, these patients were followed up periodically at our hospital's outpatient clinic. The study was approved by the Institutional Review Board of Tokushima University Hospital and performed in accordance with the ethical standards established in the 1964 Declaration of Helsinki and later amendments. Informed consent was obtained from all patients prior to the study.

\section{LEMS measurement}

We evaluated LEMS by measuring the muscle power of the quadriceps femoris (QF) using a hand-held dynamometer ( $\mu$-TAS F-1; ANIMA, Tokyo, Japan) $[10,11]$. The patient sat on a training bench with their feet hanging slightly above the floor with their knee joint at $90^{\circ}$. The trunk was perpendicular to the bench and both hands touched the bench surface on either side of the trunk. The dynamometer was attached to the distal surface of the tibia and a belt secured the dynamometer to one of the bench legs.

The patient performed knee extension with maximum effort for $5 \mathrm{~s}$. Isometric knee extension force (IKEF) was measured twice bilaterally, and the average of the highest values for the right and left IKEFs were recorded. Intraclass coefficients for this method were 0.94 (95\% Cl: 0.89-0.97) [12]. The average values of the IKEF $(\mathrm{kg})$ were divided by the patient's own body weight $(\mathrm{kg})$ to account for differences in the patients' body sizes. IKEF per body weight (\%) was selected for analysis as LEMS. In all patients, LEMS was measured within 2 weeks before allo-HSCT. Measurements were performed by 4 trained physiotherapists.

\section{Study endpoints and variables}

The patients' clinical and follow-up data were obtained from medical records. OS and NRM were set as the endpoint at 5 years follow-up. OS was defined as time from the date of transplantation to the date of death. NRM was defined as death from any cause in continuous complete remission or no progression. Acute GVHD was diagnosed and graded according to the criteria described previously [13]. Respiratory failure was defined as requiring mechanical ventilation, and renal failure as requiring renal replacement therapy. We collected the following variables: age, sex, body mass index (BMI), diagnosis, disease risk, time from diagnosis to transplant, comorbidity (hematopoietic cell transplantation comorbidity index; 
$\mathrm{HCT}-\mathrm{Cl}$ ), stem cell source, graft types, conditioning regimen, GVHD prophylaxis, nutritional status (Mini Nutritional Assessment - Short Form), and general condition (Eastern Cooperative Oncology Group Performance Status [PS]).

\section{Statistical analyses}

The patients were divided into 3 groups according to tertiles of their baseline LEMS. The IKEF per body weight in the low tertile (low LEMS) group was 15.1\%-34.1\% in females and $25.6 \%-46.6 \%$ in males, that in the middle tertile (middle LEMS) group was 34.8\%-50.1\% in females and $46.7 \%-59.6 \%$ in males, and that in the high tertile (high LEMS) group was 51.3\%-66.7\% in females, 62.8\%-92.7\% in males. Patient characteristics were compared between the LEMS groups using Fisher's exact test for categorical variables and ANOVA for continuous variables. The probability of OS was estimated using the KaplanMeier method, and the log-rank test was used to evaluate differences between the groups. Cox proportional-hazards regression model was used to analyze OS. The probability of NRM was estimated using cumulative incidence curves, with relapse defined as a competing risk. The Fine and Gray method was used to evaluate the differences between the groups.

Evaluated variables were as follows: patient age at transplantation (age $\geq 50$ vs < 50 years), sex (female vs male), BMI (underweight [ $\left.<18.5 \mathrm{~kg} / \mathrm{m}^{2}\right]$ vs normal [18.5-25.0 kg/m²] vs overweight $\left[\geq 25.0 \mathrm{~kg} / \mathrm{m}^{2}\right]$ ) [14], nutritional status (undernourished [ $\leq 7$ points] vs risk of undernourishment [8-11 points] vs normal $[\geq 12$ points]) $[15,16]$, disease risk (standard risk vs high risk) [14], HCT-Cl (0 vs 1-2 vs $\geq 3$ ) [17], graft type (matched vs not fully matched), stem cell source (related vs unrelated bone marrow vs unrelated cord blood), and conditioning regimens (myeloablative vs reduced intensity) [18]. Disease risk was defined as first or second complete remission of acute leukemia, first or second chronic phase of chronic myeloid leukemia, myelodysplastic syndrome refractory anemia or refractory cytopenia with multilineage dysplasia, or nonmalignant diseases were standard risk and other malignancies were high risk. In multivariate analyses, we included variables with $p<0.1$ in univariate analyses. Post-transplant acute adverse events were compared between the LEMS groups using Fisher's exact test. When a significant difference was detected, Bonferroni correction was applied. All statistical tests were two-sided, and $p<$ 0.05 was considered significant. All statistical analyses were performed using EZR Ver. 1.54 (Saitama Medical Center, Jichi Medical University, Saitama, Japan), which is a graphical user interface for R (The R Foundation for Statistical Computing, Vienna, Austria).

\section{Results}

The characteristics of all 86 patients, grouped according LEMS, are shown in Table 1. All patients underwent their first HSCT. Median age was 54 (range, 18-70) years, and median follow-up period of survivors was 431.5 days. There were no significant differences between groups except for nutrition status $(p=0.026)$ and performance status $(p<0.001)$. Notably, $24.1 \%$ of patients in the low LEMS group were PS 2-4, but all patients in the middle and high LEMS groups were PS 0-1. For nutritional status, the 
proportion of undernourished patients in the low LEMS group was slightly higher than in all the other groups.

The probability of OS at 5 years after allo-HSCT was $26.0 \%$ in the low LEMS group, $36.5 \%$ in the middle LEMS group, and $72.5 \%$ in the high LEMS group ( $p=0.0016$, Figure $1 \mathrm{a})$. Multivariate analysis for overall mortality showed that older age $(\mathrm{HR}=2.61,95 \% \mathrm{Cl}=1.25-5.48, p=0.011)$, high disease risk $(\mathrm{HR}=2.42$, $95 \% \mathrm{Cl}=1.11-5.25, p=0.025), \mathrm{PS} 2-4(\mathrm{HR}=2.69,95 \% \mathrm{Cl}=1.02-7.12, p=0.046)$, the middle LEMS group $(\mathrm{HR}=2.68,95 \% \mathrm{Cl}=1.08-6.69, p=0.034)$ and the low LEMS group $(\mathrm{HR}=2.98,95 \% \mathrm{Cl}=1.18-7.49, p=$ 0.020 ) were independently associated with risk of mortality (Table 2). The cumulative incidence of NRM at 5 years was $40.9 \%$ in the low LEMS group, $32.0 \%$ in the middle LEMS group, and $6.9 \%$ in the high LEMS group ( $p=0.0189$, Figure $1 b$ ). Multivariate analysis for NRM showed that the low LEMS group (HR $=5.62,95 \% \mathrm{Cl}=1.10-28.76, p=0.038)$ was independently associated with risk of NRM (Table 3 ).

In acute adverse events after allo-HSCT, the incidences of acute GVHD ( $\geq$ Grade 2) and sepsis were significantly higher in the low LEMS group than in the high LEMS group (Table 4). In the other items, the incidences were highest in the low LEMS group and lowest in the high LEMS group.

\section{Discussion}

This study is the first to investigate the impact of muscle strength on OS and NRM in patients who have undergone allo-HSCT. We found that pre-transplant LEMS significantly influenced post-transplant clinical outcome. The middle and low LEMS groups showed a significantly lower rate of OS than the high LEMS group, and the 5-year survival rate in the high LEMS group was 2.0-fold that of the middle LEMS group and 2.8-fold that of the low LEMS group. The incidences of post-transplant acute GVHD ( $\geq$ Grade 2 ) and sepsis were significantly different between the groups. As a result, the incidence of NRM was significantly higher in the low LEMS group than in the high LEMS group.

Measuring LEMS using the hand-held dynamometer evaluates pre-transplant physical function easily, objectively, and quantitatively. This measurement may help predict the mortality risks of transplantation that could not be detected by previously reported methods. Previous studies have assessed physical function by patient self-assessment [3] or as observed by a medical doctor [2, 14]. Wood et al. [3] reported on the relationship between pre-transplant physical function and post-transplant outcome using the physical component summary of the Short Form 36 Health Questionnaire. A 10-point decrease in the physical component summary was a significant predictive factor for OS $(\mathrm{HR}=1.40,95 \% \mathrm{Cl}=1.18-1.66, p$ $<0.001$ ); however, no statistical difference in a 2-year survival curve was reported. Sorror et al. [2] reported on the impact of the Karnofsky performance status and HCT-Cl on clinical outcomes, and found that the impact of the Karnofsky performance status $(\leq 80 \%)$ alone does not have a significant impact on NRM $(H R=1.45, P=0.13)$ and $O S(H R=1.42, P=0.05)$. Fuji et al. [14] reported that $P S \geq 2$ was a significant risk factor for NRM $(H R=1.44,95 \% \mathrm{Cl}=1.26-1.63, p<0.001)$ and $\mathrm{OS}(\mathrm{HR}=1.77,95 \% \mathrm{Cl}=1.60-1.96, p<$ 0.001 ). In the present study, although all patients in the middle LEMS group were PS 0 or 1 , they were found to be at risk of OS and NRM. Therefore, objective assessment of LEMS could provide useful 
information for decision making when evaluating not only for patients with poor PS, but also for patients with relatively good PS. Furthermore, increasing the physical status of such patients should be one of the aims of pre-transplant rehabilitation.

Proinflammatory cytokines and immune function may be related to LEMS and the development of posttransplant adverse events. A significant association between decreased LEMS and increased TNF- $a$ and IL-6 has been reported in older Caucasians [19]. At 1 week after all-HSCT, increased levels of TNF-a receptor I, a surrogate marker for TNF-a, is strongly correlated with the later development of GVHD [20]. IL6 is also associated with the development of GVHD [21]. Patients in the low or middle LEMS groups may have increased TNF- $a$ and IL-6 levels due to decreased muscle strength, which may lead to the development of GVHD. The GVHD is itself a risk factor for mortality [22], and systemic steroid therapy for GVHD treatment can cause infection [23]. Muscle strength itself is a risk factor for mortality in various clinical populations [24-27]. In the present study, the incidence of sepsis, thrombotic microangiopathy and/or veno-occulusive disease, and respiratory failure increased as muscle strength decreased, and the incidence of NRM within 1 year was significantly higher in the low LEMS group than in the middle and high LEMS groups.

Patients undergoing allo-HSCT have many factors that reduce muscle strength before transplantation, including induction and consolidation therapy. During that period, patients experience disuse syndrome due to fatigue, which causes nutritional disturbance due to nausea. LEMS in patients undergoing HSCT has already declined pre-transplantation $[10,11]$. The median period between diagnosis and transplantation in this study was 7 months in all LEMS groups, and adequate physical exercise and good nutritional control during that period could improve the outcome of allo-HSCT.

This study has several limitations. First, this was a single institutional and small cohort study, so future multi-center studies with larger cohorts are necessary. Second, we measured and analyzed the muscle strength of only the knee extensors, but comprehensive assessment and analysis of the skeletal muscles (including muscle mass) are required to clarify the impact of sarcopenia on post-transplant outcomes. Third, patients whose muscle strength was not measured pre-transplantation and were excluded from the study may have had a poor medical condition and prognosis, which may also have influenced outcomes.

In conclusion, LEMS before allo-HSCT was associated with post-transplant acute adverse events and could be a predictor of OS and NRM. Encouraging patient physical activity and maintaining muscle strength pre-transplantation could lead to improved post-transplant outcomes.

\section{Declarations}

Acknowledgments: We thank the staff in the Department of Rehabilitation at Tokushima University Hospital who helped with taking measurements. We also thank all the patients for their participation in this study. 
Author contributions: SK and TS designed, analyzed, interpreted the data and wrote the manuscript. KK, MO, KS, TH, SF, SN, HM, NS, RO, MA and SK contributed with data collection and commented on the manuscript. All authors read and approved the final manuscript.

Funding: No funds, grants, or other support was received.

\section{Compliance with ethical standards}

Conflict of interest: The authors declare that there are no conflicts of interest to declare that are relevant to the content of this article.

Ethics approval: The study was approved by the Institutional Review Board of Tokushima University Hospital (3108-1) and was performed in accordance with the ethical standards as laid down in the 1964 Declaration of Helsinki and its later amendments.

Consent to participate: Informed consent was obtained from all patients prior to the study.

Availability of data and material: Not applicable.

Code availability: Not applicable.

Consent for publication: Informed consent was obtained from all patients prior to the study.

\section{References}

1. The Japanese Data Center for Hematopoietic Cell Transplantation/The Japan Society for Hematopoietic Cell Transplantation Hematopoietic Cell Transplantation in Japan. Annual Report of Nationwide Survey 2019. http://www.jdchct.or.jp/data/report/2019/. Accessed 26 May 2020

2. Sorror M, Storer B, Sandmaier BM, et al (2008) Hematopoietic cell transplantation-comorbidity index and Karnofsky performance status are independent predictors of morbidity and mortality after allogeneic nonmyeloablative hematopoietic cell transplantation. Cancer 112:1992-2001. https://doi.org/10.1002/cncr.23375

3. Wood WA, Le-Rademacher J, Syrjala KL, et al (2016) Patient-reported physical functioning predicts the success of hematopoietic cell transplantation (BMT CTN 0902). Cancer 122:91-98. https://doi.org/10.1002/cncr.29717

4. Leong DP, Teo KK, Rangarajan S, et al (2015) Prognostic value of grip strength: findings from the Prospective Urban Rural Epidemiology (PURE) study. Lancet Lond Engl 386:266-273. https://doi.org/10.1016/S0140-6736(14)62000-6

5. Zhuang C-L, Zhang F-M, Li W, et al (2020) Associations of low handgrip strength with cancer mortality: a multicentre observational study. J Cachexia Sarcopenia Muscle 11:1476-1486. https://doi.org/10.1002/jcsm.12614 
6. Ando T, Fujisawa S, Teshigawara H, et al (2020) Computed tomography-defined sarcopenia: prognostic predictor of nonrelapse mortality after allogeneic hematopoietic stem cell transplantation: a multicenter retrospective study. Int J Hematol 112:46-56. https://doi.org/10.1007/s12185-02002870-5

7. Sakatoku K, Ito A, Tajima K, et al (2020) Prognostic significance of low pre-transplant skeletal muscle mass on survival outcomes in patients undergoing hematopoietic stem cell transplantation. Int $\mathrm{J}$ Hematol 111:267-277. https://doi.org/10.1007/s12185-019-02773-0

8. Armenian SH, Xiao M, Berano Teh J, et al (2019) Impact of Sarcopenia on Adverse Outcomes After Allogeneic Hematopoietic Cell Transplantation. J Natl Cancer Inst 111:837-844. https://doi.org/10.1093/jnci/djy231

9. Wehrle A, Kneis S, Dickhuth $\mathrm{H}-\mathrm{H}$, et al (2019) Endurance and resistance training in patients with acute leukemia undergoing induction chemotherapy-a randomized pilot study. Support Care Cancer Off J Multinatl Assoc Support Care Cancer 27:1071-1079. https://doi.org/10.1007/s00520-018-4396-6

10. Tanaka S, Imataki O, Kitaoka A, et al (2017) Clinical impact of sarcopenia and relevance of nutritional intake in patients before and after allogeneic hematopoietic stem cell transplantation. $J$ Cancer Res Clin Oncol 143:1083-1092. https://doi.org/10.1007/s00432-016-2336-8

11. Morishita S, Kaida K, Ikegame K, et al (2012) Impaired physiological function and health-related QOL in patients before hematopoietic stem-cell transplantation. Support Care Cancer Off J Multinatl Assoc Support Care Cancer 20:821-829. https://doi.org/10.1007/s00520-011-1156-2

12. Hirano M, Katoh M, Gomi M, Arai S (2020) Validity and reliability of isometric knee extension muscle strength measurements using a belt-stabilized hand-held dynamometer: a comparison with the measurement using an isokinetic dynamometer in a sitting posture. J Phys Ther Sci 32:120-124. https://doi.org/10.1589/jpts.32.120

13. Przepiorka D, Weisdorf D, Martin P, et al (1995) 1994 Consensus Conference on Acute GVHD Grading. Bone Marrow Transplant 15:825-828

14. Fuji S, Takano K, Mori T, et al (2014) Impact of pretransplant body mass index on the clinical outcome after allogeneic hematopoietic SCT. Bone Marrow Transplant 49:1505-1512. https://doi.org/10.1038/bmt.2014.178

15. Martucci RB, Barbosa MV, D'Almeida CA, et al (2017) Undernutrition as independent predictor of early mortality in elderly cancer patients. Nutr Burbank Los Angel Cty Calif 34:65-70. https://doi.org/10.1016/j.nut.2016.09.011

16. Kaiser MJ, Bauer JM, Uter W, et al (2011) Prospective validation of the modified mini nutritional assessment short-forms in the community, nursing home, and rehabilitation setting. J Am Geriatr Soc 59:2124-2128. https://doi.org/10.1111/j.1532-5415.2011.03659.x

17. Tanaka Y, Kurosawa S, Tajima K, et al (2016) Analysis of non-relapse mortality and causes of death over 15 years following allogeneic hematopoietic stem cell transplantation. Bone Marrow Transplant 51:553-559. https://doi.org/10.1038/bmt.2015.330 
18. Bacigalupo A, Ballen K, Rizzo D, et al (2009) Defining the intensity of conditioning regimens: working definitions. Biol Blood Marrow Transplant J Am Soc Blood Marrow Transplant 15:1628-1633. https://doi.org/10.1016/j.bbmt.2009.07.004

19. Visser M, Pahor M, Taaffe DR, et al (2002) Relationship of Interleukin-6 and Tumor Necrosis Factor-a With Muscle Mass and Muscle Strength in Elderly Men and WomenThe Health ABC Study. J Gerontol Ser A 57:M326-M332. https://doi.org/10.1093/gerona/57.5.M326

20. Ferrara JLM, Levine JE, Reddy P, Holler E (2009) Graft-versus-host disease. Lancet Lond Engl 373:1550-1561. https://doi.org/10.1016/S0140-6736(09)60237-3

21. Tvedt TH, Lie SA, Reikvam H, et al (2016) Pretransplant Levels of CRP and Interleukin-6 Family Cytokines; Effects on Outcome after Allogeneic Stem Cell Transplantation. Int J Mol Sci 17:. https://doi.org/10.3390/ijms17111823

22. Jaglowski SM, Devine SM (2014) Graft-versus-Host Disease: Why Haven't We Made More Progress? Curr Opin Hematol 21:141-147. https://doi.org/10.1097/MOH.0000000000000026

23. García-Cadenas I, Rivera I, Martino R, et al (2017) Patterns of infection and infection-related mortality in patients with steroid-refractory acute graft versus host disease. Bone Marrow Transplant 52:107113. https://doi.org/10.1038/bmt.2016.225

24. Volaklis KA, Halle M, Meisinger C (2015) Muscular strength as a strong predictor of mortality: A narrative review. Eur J Intern Med 26:303-310. https://doi.org/10.1016/j.ejim.2015.04.013

25. Ali NA, O'Brien JM, Hoffmann SP, et al (2008) Acquired weakness, handgrip strength, and mortality in critically ill patients. Am J Respir Crit Care Med 178:261-268. https://doi.org/10.1164/rccm.200712$18290 \mathrm{C}$

26. Wang $\mathrm{C}-\mathrm{H}$, Lin $\mathrm{H}-\mathrm{C}$, Chang $\mathrm{Y}-\mathrm{C}$, et al (2017) Predictive factors of in-hospital mortality in ventilated intensive care unit. Medicine (Baltimore) 96:. https://doi.org/10.1097/MD.0000000000009165

27. Xavier SP, Goes CR, Bufarah MNB, et al (2017) Handgrip strength and weight predict long-term mortality in acute kidney injury patients. Clin Nutr ESPEN 17:86-91. https://doi.org/10.1016/j.clnesp.2016.09.006

\section{Tables}


Table 1 Patient characteristics

Variable

Age (years)

Median (range)

Sex

Female

Male

BMI $\left(\mathrm{kg} / \mathrm{m}^{2}\right)$

Underweight

Normal

Overweight

Diagnosis

$\mathrm{AML}^{\mathrm{C}}$
$\mathrm{ALL} / \mathrm{LBL}$
$\mathrm{MDS}$
$\mathrm{CML}$
$\mathrm{ML}$
Other

Disease risk

Standard

High

Time from diagnosis to transplant (months)

Median (IQR)

HCT-Cl

0

$1-2$

$$
\begin{array}{lll}
\text { Low LEMS } & \begin{array}{l}
\text { Middle } \\
\text { LEMS }
\end{array} & \text { High LEM } \\
\mathrm{n}=29 & \mathrm{n}=28 & \mathrm{n}=29
\end{array}
$$

High LEMS $p$ value

0.373

$54.0(26-\quad 57.5(1870) \quad 50(1869)$

70)

1.000

\begin{tabular}{lll}
$11(37.9 \%)$ & $11(39.3 \%)$ & $12(41.4 \%)$ \\
\hline $18(62.1 \%)$ & $17(60.7 \%)$ & $17(58.6 \%)$
\end{tabular}

0.124

$2(6.9 \%) \quad 2(7.1 \%) \quad 4(13.8 \%)$

$19(65.5 \%) \quad 22(78.6 \%) \quad 24(82.8 \%)$

$8(27.6 \%) \quad 4(14.3 \%) \quad 1(3.4 \%)$

0.982

$12(41.4 \%) \quad 12(42.9 \%) \quad 14(48.3 \%)$

$3(10.3 \%) \quad 2(7.1 \%) \quad 3(10.3 \%)$

$6(20.7 \%) \quad 4(14.3 \%) \quad 5(17.2 \%)$

$2(3.4 \%) \quad 2(7.1 \%) \quad 2(6.9 \%)$

$5(17.2 \%) \quad 5(17.9 \%) \quad 2(6.9 \%)$

$2(6.9 \%) \quad 3(10.7 \%) \quad 3(10.3 \%)$

0.077

$6(20.7 \%) \quad 11(39.3 \%) \quad 14(48.3 \%)$

$23(79.3 \%) \quad 17(60.7 \%) \quad 15(51.7 \%)$

0.489

$7(5-10) \quad 7(5-9) \quad 7(6-14)$

0.721

$10(34.5 \%) \quad 14(50.0 \%) \quad 15(51.7 \%)$

$13(44.8 \%) \quad 10(35.7 \%) \quad 10(34.5 \%)$ 


\begin{tabular}{|c|c|c|c|c|}
\hline 3 or higher & $6(13.8 \%)$ & $4(14.3 \%)$ & $4(13.8 \%)$ & \\
\hline Stem cell source & & & & 0.779 \\
\hline Related PB & $7(24.1 \%)$ & $6(21.4 \%)$ & $7(24.1 \%)$ & \\
\hline Unrelated PB & $1(3.4 \%)$ & $0(0.0 \%)$ & $2(6.9 \%)$ & \\
\hline Unrelated BM & $15(51.7 \%)$ & 20 (71.4\%) & $12(41.4 \%)$ & \\
\hline Unrelated CB & $6(20.7 \%)$ & $2(7.1 \%)$ & $8(27.6 \%)$ & \\
\hline Graft type & & & & 0.399 \\
\hline Matched & $19(65.5 \%)$ & $22(78.6 \%)$ & $18(62.1 \%)$ & \\
\hline Not fully matched & $10(34.5 \%)$ & $6(21.4 \%)$ & $11(37.9 \%)$ & \\
\hline Conditioning regimen & & & & 0.603 \\
\hline Myeloablative & $20(69.0 \%)$ & $20(71.4 \%)$ & $17(58.6 \%)$ & \\
\hline Reduced-intensity & $9(31.0 \%)$ & $8(28.6 \%)$ & $12(41.4 \%)$ & \\
\hline GVHD prophylaxis & & & & 1.000 \\
\hline CSP-based & $5(17.2 \%)$ & $5(17.9 \%)$ & $5(17.2 \%)$ & \\
\hline TAC-based & $24(82.8 \%)$ & $23(82.1 \%)$ & $23(82.8 \%)$ & \\
\hline Nutritional status & & & & 0.026 * \\
\hline Undernourished & $6(20.7 \%)$ & $0(0.0 \%)$ & $1(3.4 \%)$ & \\
\hline $\begin{array}{l}\text { At risk of } \\
\text { undernourishment }\end{array}$ & $17(58.6 \%)$ & $15(53.6 \%)$ & $16(55.2 \%)$ & \\
\hline Normal & $6(20.7 \%)$ & $13(46.4 \%)$ & $12(41.4 \%)$ & \\
\hline Performance status & & & & $\begin{array}{l}<0.001 \\
*+\end{array}$ \\
\hline $0-1$ & $22(75.9 \%)$ & $28(100.0 \%)$ & $\begin{array}{l}29 \\
(100.0 \%)\end{array}$ & \\
\hline $2-4$ & $7(24.1 \%)$ & $0(0.0 \%)$ & $0(0.0 \%)$ & \\
\hline
\end{tabular}

*Significant difference between low and middle LEMS groups

†Significant difference between low and high LEMS groups

$L E M S$, lower extremity muscle strength; $B M I$, body mass index; $A M L$, acute myeloid leukemia; $A L L$, acute lymphocytic leukemia; $L B L$, lymphoblastic lymphoma; $M D S$, myelodysplastic syndrome; $C M L$, chronic myelogenous leukemia; IQR, interquartile range; $H C T-C l$, hematopoietic cell transplantation-comorbidity 
index; $P B$, peripheral blood; $B M$, bone marrow; $C B$, cord blood; $G V H D$, graft versus host disease; $C S P$, cyclosporine; TAC, tacrolimus 
Table 2 Univariate and multivariate analyses for overall mortality

$\begin{array}{lll}\text { Univariate } & \text { Multivariate } \\ \mathrm{HR}(95 \% \mathrm{Cl}) & \text { p value } & \mathrm{HR}(95 \% \mathrm{Cl}) \quad p \text { value }\end{array}$

Age (years)

\begin{tabular}{|lllll|}
\hline$<50$ & 1 & 1 & \\
$\geq 50$ & $3.03(1.486 .22)$ & 0.002 & $2.61(1.255 .48)$ & 0.011 \\
\hline Sex & & & & \\
\hline
\end{tabular}

Female $\quad 1$

$\begin{array}{lll}\text { Male } & 1.19(0.632 .25) & 0.591\end{array}$

BMI

\begin{tabular}{|lll}
\hline Underweight & $0.78(0.242 .59)$ & 0.696 \\
\hline Normal & 1 & \\
\hline Overweight & $1.24(0.572 .72)$ & 0.582 \\
\hline Nutritional status & & \\
\hline Normal & 1 & \\
\hline At risk of & $1.07(0.532 .15)$ & 0.851 \\
undernourishment & & \\
\hline Undernourished & $2.09(0.745 .94)$ & 0.167 \\
\hline Disease risk & 1 & \\
\hline Standard & $2.97(1.416 .24)$ & 0.004 \\
\hline High & & \\
\hline HCT-Cl & 1 & \\
\hline 0 & $1.28(0.652 .52)$ & 0.470 \\
\hline $1-2$ & $1.23(0.513 .00)$ & 0.643 \\
\hline 3 or higher & $1.20(0.622 .32)$ & 0.599 \\
\hline Graft type & & \\
\hline Matched & & \\
\hline Not fully matched & & \\
\hline Conditioning regimen & & \\
\hline
\end{tabular}




\begin{tabular}{|c|c|c|c|c|}
\hline Myeloablative & 1 & & & \\
\hline Reduced intensity & $1.17(0.612 .27)$ & 0.640 & & \\
\hline \multicolumn{5}{|l|}{ Stem cell source } \\
\hline Related & 1 & & & \\
\hline Unrelated BM & $1.45(0.653 .23)$ & 0.345 & & \\
\hline Unrelated CB & $1.44(0.533 .84)$ & 0.467 & & \\
\hline \multicolumn{5}{|l|}{ Performance status } \\
\hline $0-1$ & 1 & & 1 & \\
\hline $2-4$ & $6.55(2.7815 .43)$ & $<0.001$ & $2.69(1.027 .12)$ & 0.046 \\
\hline \multicolumn{5}{|l|}{ LEMS } \\
\hline High & 1 & & 1 & \\
\hline Middle & $2.54(1.026 .30)$ & 0.044 & $2.68(1.086 .69)$ & 0.034 \\
\hline Low & $4.34(1.8210 .29)$ & 0.001 & $2.98(1.187 .49)$ & 0.020 \\
\hline
\end{tabular}

$H R$, hazard ratio; $C l$, confidence interval; $B M I$, body mass index; $H C T-C l$, hematopoietic cell transplantationcomorbidity index; $B M$, bone marrow; $C B$, cord blood; $L E M S$, lower extremity muscle strength 
Table 3 Univariate and multivariate analyses for non-relapse mortality (NRM)

\begin{tabular}{|c|c|c|c|c|}
\hline & \multicolumn{2}{|l|}{ Univariate } & \multicolumn{2}{|l|}{ Multivariate } \\
\hline & $\mathrm{HR}(95 \% \mathrm{Cl})$ & $p$ value & $\mathrm{HR}(95 \% \mathrm{Cl})$ & $p$ value \\
\hline \multicolumn{5}{|l|}{ Age (years) } \\
\hline$<50$ & 1 & & & \\
\hline$\geq 50$ & $2.27(0.826 .29)$ & 0.110 & & \\
\hline \multicolumn{5}{|l|}{ Sex } \\
\hline Female & 1 & & & \\
\hline Male & $1.55(0.604 .00)$ & 0.360 & & \\
\hline \multicolumn{5}{|l|}{ BMI } \\
\hline Underweight & $0.58(0.064 .90)$ & 0.620 & & \\
\hline Normal & 1 & & & \\
\hline Overweight & $1.31(0.453 .77)$ & 0.620 & & \\
\hline \multicolumn{5}{|l|}{ Nutritional status } \\
\hline Normal & 1 & & & \\
\hline $\begin{array}{l}\text { At risk of } \\
\text { undernourishment }\end{array}$ & $0.61(0.251 .50)$ & 0.280 & & \\
\hline Undernourished & $0.43(0.043 .88)$ & 0.450 & & \\
\hline \multicolumn{5}{|l|}{ Disease risk } \\
\hline Standard & 1 & & 1 & \\
\hline High & $2.70(0.977 .54)$ & 0.058 & $2.07(0.725 .93)$ & 0.180 \\
\hline \multicolumn{5}{|l|}{$\mathrm{HCT}-\mathrm{Cl}$} \\
\hline 0 & 1 & & & \\
\hline $1-2$ & $0.99(0.412 .39)$ & 0.990 & & \\
\hline 3 or higher & $0.25(0.031 .98)$ & 0.190 & & \\
\hline \multicolumn{5}{|l|}{ Graft type } \\
\hline Matched & 1 & & & \\
\hline Not fully matched & $0.72(0.271 .96)$ & 0.520 & & \\
\hline Conditioning regimen & & & & \\
\hline
\end{tabular}




\begin{tabular}{|c|c|c|c|c|}
\hline Myeloablative & 1 & & & \\
\hline Reduced intensity & $1.30(0.523 .24)$ & 0.580 & & \\
\hline \multicolumn{5}{|l|}{ Stem cell source } \\
\hline Related & 1 & & & \\
\hline Unrelated BM & $1.08(0.373 .10)$ & 0.89 & & \\
\hline Unrelated CB & $0.48(0.092 .51)$ & 0.390 & & \\
\hline \multicolumn{5}{|l|}{ Performance status } \\
\hline $0-1$ & 1 & & & \\
\hline $2-4$ & $2.43(0.688 .70)$ & 0.170 & & \\
\hline \multicolumn{5}{|l|}{ LEMS } \\
\hline High & 1 & & 1 & \\
\hline Middle & $4.01(0.8219 .69)$ & 0.087 & $3.76(0.76-18.67)$ & 0.110 \\
\hline Low & $6.70(1.4231 .48)$ & 0.016 & $5.62(1.10-28.76)$ & 0.038 \\
\hline
\end{tabular}

$H R$, hazard ratio; $C l$, confidence interval; $B M I$, body mass index; $H C T-C l$, hematopoietic cell transplantationcomorbidity index; $B M$, bone marrow; $C B$, cord blood; $L E M S$, lower extremity muscle strength

\begin{tabular}{|lllll|}
\hline \multicolumn{3}{|l|}{ Table 4 Acute adverse events after transplantation } & & \\
& $\begin{array}{l}\text { Low LEMS } \\
(\mathrm{n}=29)\end{array}$ & $\begin{array}{l}\text { Middle LEMS } \\
(\mathrm{n}=28)\end{array}$ & $\begin{array}{l}\text { High LEMS } \\
(\mathrm{n}=29)\end{array}$ & $p$ value \\
\hline Acute GVHD $\geq$ Grade 2 & $20(69.0 \%)$ & $15(53.6 \%)$ & $9(31.0 \%)$ & $0.014^{*}$ \\
\hline Acute GVHD $\geq$ Grade 3 & $6(20.7 \%)$ & $10(35.7 \%)$ & $3(10.3 \%)$ & 0.074 \\
\hline Sepsis & $16(55.2 \%)$ & $7(25.0 \%)$ & $4(13.8 \%)$ & $0.002^{\star}$ \\
\hline Respiratory failure & $6(20.7 \%)$ & $5(17.9 \%)$ & $0(0.0 \%)$ & 0.024 \\
\hline Renal failure & $5(17.2 \%)$ & $2(7.1 \%)$ & $0(0.0 \%)$ & 0.047 \\
\hline
\end{tabular}

*Significant difference between low and high LEMS groups

$L E M S$, lower extremity muscle strength; $G V H D$, graft versus host disease

\section{Figures}


( a)

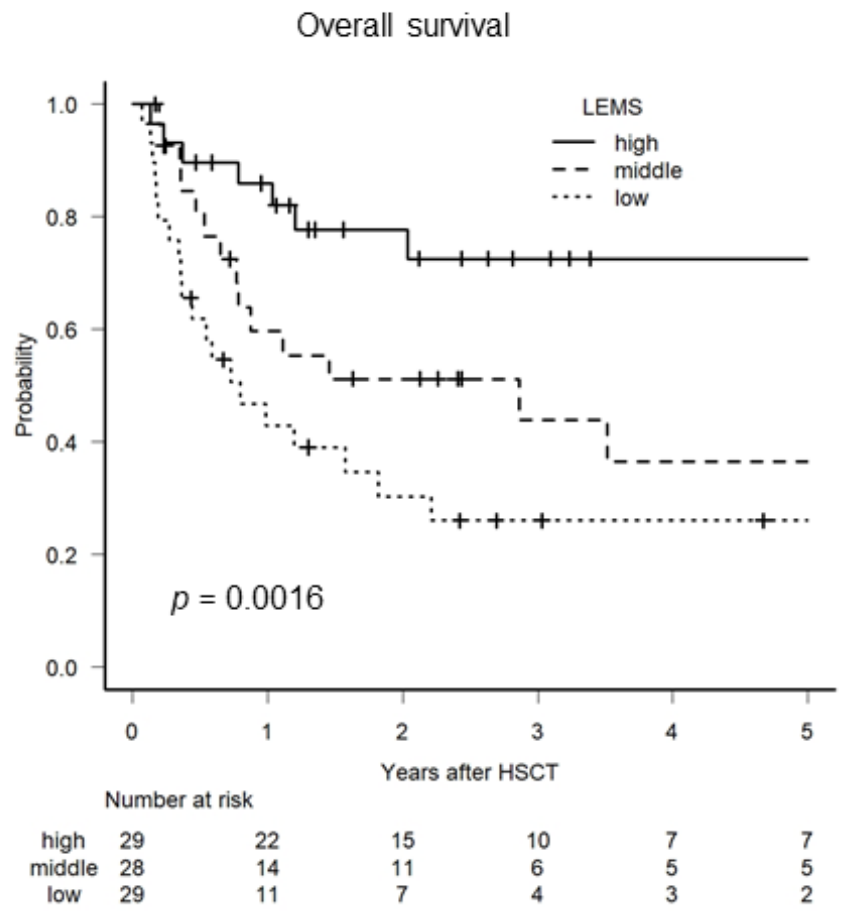

(b)

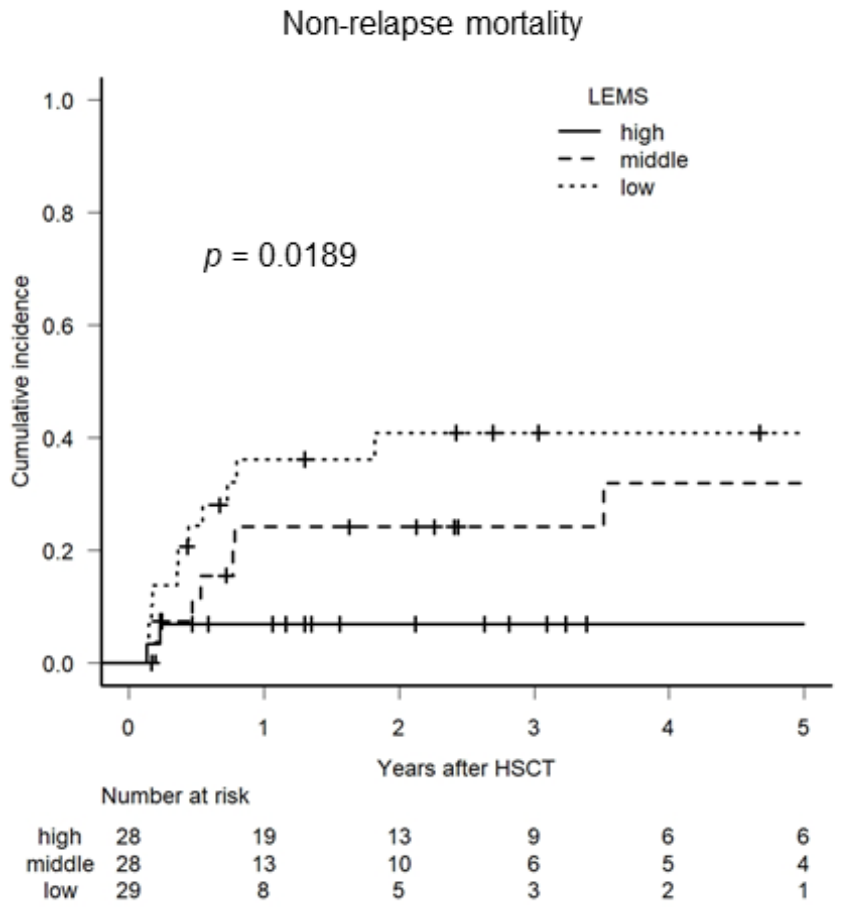

\section{Figure 1}

(a) Probability of overall survival and (b) cumulative incidence of non-relapse mortality in patients with low, middle, and high pre-transplant lower extremity muscle strength 